\title{
Conditional Deliberation: The Case of Joint Parliamentary Committees in the EU*
}

SAIME OZCURUMEZ and JULINDA HOXHA

Bilkent University

\begin{abstract}
Deliberation, as a mode of interaction based on the logic of reason-giving argumentation, is a core feature of the European Union institutions. Yet only few studies have explored the conditions that make deliberation possible in practice. This study examines the institutional determinants of deliberation within joint parliamentary committees (JPCs) - longstanding instruments of EU enlargement policy. The empirical analysis reveals a dynamic relationship between 'deliberation' and 'debate' as extreme modes of interaction that co-exist within the same setting. It also suggests that deliberation is a product of participants' constant efforts to maintain equal power relations and low issue-area sensitivity. This study provides new evidence on deliberative politics at the EU level. In addition, it highlights the role of inter-parliamentary deliberation as a catalyst for political co-operation and policy co-ordination, at a time of intensifying enlargement fatigue and growing Euroscepticism both at home and abroad.
\end{abstract}

\section{Introduction}

Scholars theorizing deliberative politics have increasingly identified the European Union institutions as constituting exemplary venues of deliberation. Very few, however, have turned to explaining how deliberation plays out in practice. Those works that focus on the empirical conditions of deliberation examined either intergovernmental (EU Council and the Council of the EU) or supranational (comitology) deliberation, largely neglecting the role of the European Parliament (EP), which to many would be the most likely venue for deliberative policy-making. Moreover, inter-parliamentary interaction in the EU, which would have been the prime candidate for deliberation to emerge, has been overlooked altogether. This study examines joint parliamentary committees (JPCs), themselves institutions of inter-parliamentary interaction within the context of enlargement, as a prototypical model of deliberation. By empirically studying modes of interaction in the JPCs, this research aims to bring new insights into theories of deliberation. In order to do so, we examine the transcripts of JPC meetings carried out in the accession process of Bulgaria, Romania, Lithuania, Croatia and Turkey for the years between 2000 and 2008. We aim to examine the conditions under which deliberation thrives.

JPCs are as old as the EU's enlargement project itself. Despite their prominence and continuity, however, little is known about the role of JPC delegations as institutions of inter-parliamentary co-operation. These committees operate as policy instruments that

\footnotetext{
* The authors are grateful to two anonymous referees for their useful comments, and Banu Demir Pakel, Cavit Pakel, Tolga Bolukbasi, Zeki Sarıil for their helpful suggestions on the earlier versions of the article.
} 
contribute to the ongoing dialogue between the EU and the candidate countries through formal and regular meetings between the delegations appointed by the EP and respective national parliaments. In addition to the parliamentary representatives, each JPC meeting brings together representatives from the EU Commission, the Council, national governments and, at times, representatives of civil society organizations. Co-operation between the EP and national parliaments is launched when a country submits its application for membership to join the EU, and continues throughout the accession process until EU membership. The EU itself defines the JPC as 'a focused interlocutor at the heart of the European Union'; 'a framework within which controversial issues can be aired' with 'an element of transparency'; and 'a test of how deep parliamentary democracy with pluralism [has] taken root'.

Debates in the JPC meetings follow accession negotiations that take place at the intergovernmental level between the national governments and the Commission. The MPs participating in the JPC review the progress reports, voice their criticisms of the Commission's policy formulations, discuss the implementation of EU level policies at the national level and provide policy input through joint declarations and recommendations. The main objectives of these meetings are 'to exercise parliamentary oversight of all aspects of bilateral relations between the EU and to examine in detail the progress in the accession preparations and negotiations'. ${ }^{2}$ JPCs are consultative bodies - that is, they can only indirectly affect the process of policy-making through reports sent to the Council, the Commission and candidate country governments. Despite their limited formal powers and legally non-binding decisions, JPCs remain resilient. They provide participants an equal chance to persuade each other through reason-giving argumentation or deliberation.

The point of departure for this study is our observation that JPCs constitute prototypical venues where normative deliberative ideals are translated into political practices. By empirically studying the conditions allowing deliberation in the JPCs, which are most likely cases of deliberation in the EU, we aim to contribute to the literature on EU politics in two ways. First, we bridge the existing gap between deliberative theory and how deliberation actually works by modelling deliberation in inter-parliamentary interaction in the JPCs. Informed by the existing literature we identify conditions shaping the mode of interaction in these settings, and based on these conditions explain the interplay between deliberation and other modes of interaction. Second, we show how the enlargement process is deliberated by parliamentarians in addition to being negotiated by technocrats at the intergovernmental level. By doing so, we reveal that deliberation is at least as consequential as negotiation in the enlargement process although the scholarly literature on enlargement almost exclusively emphasizes the latter.

Based on our analysis, we conclude that the likelihood of deliberation in JPCs increases with positive membership prospect and low issue-area sensitivity. This study, first, contributes to the literature on deliberation by accounting for under what conditions and to what extent other speech acts such as debate exist in deliberative settings. Second, the conditions for inter-parliamentary interaction (issue-area sensitivity, membership

\footnotetext{
${ }^{1}$ For more details, see the European Parliament official website, Archives of the Activities of Former Delegations. The document title is: 'Summary of activities/achievements of the Division Europe during the legislative period 1999-2004': «http://www.europarl.europa.eu/intcoop/euro/activities_2004.pdf».

${ }^{2}$ For more details, see 'The European Union in the Enlargement Process: An Overview'. Available at: «http:// www.europarl.europa.eu/enlargement/positionep/ep_overview_en.htm».
} 
prospect and conditionality), which have been developed in this study, may help explain the nature of deliberation in deliberative settings other than JPCs in the EU and elsewhere where deliberation takes place.

The study is organized as follows. The next section presents inter-parliamentary co-operation in JPCs as a new model of deliberation, which has neither been examined analytically nor investigated empirically in the EU literature. Then there is an empirical analysis of minutes of JPC meetings for five countries (Bulgaria, Croatia, Lithuania, Romania and Turkey) with the objective of identifying and examining the conditions that stimulate or restrain deliberation in the JPCs. It does so through qualitative content analysis of 45 legislative transcripts produced in the JPC meetings (2000-7) supported by quantitative analysis (OLS regression). ${ }^{3}$ Finally, the article concludes with a brief discussion of the findings and notes prospects for future research.

\section{JPCs as Institutions of Deliberative Politics}

Deliberation is a discursive process or practice widely recognized as a form of 'communication [,] in that deliberators are amenable to changing their judgments, preferences and views during the course of the interactions, which involve persuasion rather than coercion, manipulation, or deception' (Dryzek, 2000, p. 1). Since the early 1990s, an extensive body of literature has been accumulated studying deliberation, considering it as a standard form of democratic and legitimate governance both at the national and international levels (Bohman, 1998; Bohman and Rehg, 1997; Chambers, 2003; Cohen, 1996; Dryzek, 2000; Elster 1998; Gutmann and Thompson, 1996; Habermas 1996a; 1996b; 1998; Macedo, 1999; Rawls, 1993). The idea of deliberation has recently been integrated into debates about democracy at the EU level as well (Closa and Fossum, 2005; Cohen and Sabel, 1997; Eriksen, 2000; Eriksen and Fossum, 2002; Gerstenberg and Sabel, 2002; Vink, 2007). However, advocating the coherence of deliberative democracy as a desirable ideal does not 'spell out in detail the ways in which the deliberative ideal should be put into practice' (Lafont, 2006, p. 1). Therefore, many scholars have insisted on the study of the empirical conditions under which deliberation could work (Chambers, 2003; Risse 2004; Risse and Kleine, 2010; Steenbergen et al., 2003; Steiner et al., 2005; Thompson, 2008). Investigating the specific conditions that produce deliberation in practice has become the imperative for further research - shifting the focus of research toward the empirical study of deliberative institutions.

Political bodies formed by the EU have received extraordinary attention as promising institutions of deliberative politics. "[T] he EU contains . . . a rather complex "constitution" comprising both voting and bargaining procedures ... and procedures for ensuring both public and institutionalized deliberations' (Eriksen, 2000, p. 62). Public deliberations at the EU level are not practically feasible, especially if one considers the presence of multiple demoi or the absence of a 'European people'. Therefore, institutionalized deliberations, which take place among the political elite and do not presuppose the involvement of societal actors or the general European public, have been the focus of research among

\footnotetext{
${ }^{3}$ For more details on legislative transcripts, see the European Parliament official website, Archives of the Activities of Former Delegations. Available at: «http://www.europarl.europa.eu/activities/archives/staticDisplay.do?id=120\&language $=\mathrm{EN} »$.
} 
scholars interested in deliberation at the EU level. The EU scholars have examined elite-level deliberation in some of the existing institutions including the European Council and the Council of the EU often known as intergovernmental deliberation (Naurin, 2009; Pollack and Shaffer, 2008; Puetter, 2003; 2012: Warntjen, 2010); the open method of coordination (OMC), known as the 'new governance' in the EU (Cohen and Sabel, 2003; Jacobsson and Vifell, 2005; 2007); the comitology system often known as 'supranational deliberation' (Blom-Hansen and Brandsma 2009; Joerges, 2002; 2006; Joerges and Neyer, 1997a; 1997b); the convention method known as the 'constitutional moment, 2003-2004' (Magnette and Nicolaidis, 2004; Maurer 2003; Panke, 2006; Risse and Kleine 2007; 2010); and the European Parliament (Eriksen and Fossum, 2002; Lord and Tamvaki, 2013).

Deliberation in the parliaments, by comparison to all other EU institutions, is the least studied area of research. This is indeed surprising if one considers that deliberation is expected to characterize parliamentary settings, which by their very nature are forums where civic-minded parliamentarians share their views and justify their political positions through rational argumentation. Such deliberative interaction could be even more likely in the case of EU politics, which 'is not based on party democracy, and there is more scope for open deliberation in the EP than in fully fledged party-based systems' where parliamentarians have to act in line with partisan cleavages (Eriksen and Fossum, 2002, p. 413). Some other deliberative qualities of the EP have to do with the consensual style of politics, multidimensionality of the parliamentary field, linguistic diversity that downplay the national orientations of MEPs and foster argumentation in more universalistic terms (Eriksen and Fossum, 2002). For this study, the co-operation between the EP and national parliaments of the candidate countries - that is, the JPCs - is of particular significance. JPCs offer a remarkably rich area of research on institutionalization of deliberative ideals not only because they are largely understudied, but primarily because of the inherent deliberative qualities of these inter-parliamentary venues.

JPCs constitute ideal institutional venues for studying deliberative modes of interaction for several reasons. First, they are venues of inter-parliamentary co-operation that facilitate the articulation of different values, interests and preferences of a diverse group of participants. These institutions can best be characterized as what Crum and Fossum (2009) call a 'multilevel parliamentary field'. JPCs facilitate interaction between national (MPs and government representatives) and supranational actors (Commission representatives and MEPs); political (political parties represented through MPs) and administrative actors (civil servants and experts); state and non-state/social actors (relevant interest groups). Different participants may represent overlapping roles. Actor heterogeneity increases complexity (multidimensionality of conflict) and overlapping identities increase the levels of uncertainty (role ambiguity) in the interactions in these inter-parliamentary venues. Both of these conditions are favourable to deliberative mode of interaction (Jacobsson and Vifell, 2007; Risse and Kleine, 2010; Rittberger, 2012). Under such circumstances participants are less inclined to follow fixed policy preferences or preconceived political positions and therefore are more open to persuasion. Actors participating in a diversified political environment such as JPCs have more variable preferences and eventually are more likely to engage in deliberation.

Second, the actors involved in the JPC meetings interact with each other in a loosely organized structure. Interactions take place under no strict rules of procedure and are free 
from any central authority that could restrict the behaviour of participants. Discussions are broadly shaped by a flexible agenda which is set at the beginning of each meeting while the significance attached to every single item is left to the initiative of participants. Moreover, JPCs are not decision-making institutions and have no voting mechanisms. Meetings end with political declarations, but participants are not legally bound by the outcomes of the discussions. These institutional characteristics hint at low levels of institutionalization in the JPCs, resembling those of networks. Network actors are free in terms of expressing their views and they may change their preferences over the course of the debates. These actors do not act on the basis of strategic interest calculations aiming at acquiring desired voting outcomes or following pre-set rules of procedure. Networked forms of governance are seen as particularly promising institutions to study deliberation in the EU (Pollack and Shaffer, 2008).

Finally, interaction among actors in JPCs is characterized by some degree of transparency and publicity. From time to time, civil society associations affected by EU policy directives attend the JPCs meetings. In addition, JPC delegates can make issues public at home, spread messages to the public concerning the benefits and risks associated with EU membership, extend the dialogue with the EU political bodies to the national and subnational levels and, eventually, politicize the whole process of enlargement. Moreover, JPC minutes are published online and the main themes of discussion are broadcasted on television and published in newspapers. JPC meetings take place within in-camera settings, which are conducive to the deliberative mode of communication. Research has shown that closed, in-camera venues are in practice more favourable to deliberation (Hurrelmann and DeBardeleben, 2009; Pollack and Shaffer, 2008) because actors can freely exchange their ideas and do not have to stick to some fixed, exogenous preferences as if they have to 'stick to their guns' (Risse, 2004, p. 312).

For these reasons, inter-parliamentary interaction in the JPCs is a most likely case of institutionalized deliberation that takes place in a multilevel, loosely organized structure and in-camera setting with the necessary qualities of transparency and publicity. Studying the conditions that constrain or enable the deliberative capacity of JPCs will offer insights into deliberative dynamics of other similar parliamentary institutions which have been largely overlooked by the literature on deliberation. Upon closer investigation we observe that JPC interaction qualifies as a prototypical case of deliberation, which opens up new venues for expanding the theory of deliberation by revealing conditions for deliberative processes. We characterize this mode of interaction in the JPCs as conditional deliberation. The next step is to identify those empirical conditions favourable to deliberation in practice and explore the relationship between deliberation and other modes of parliamentary interaction.

\section{Analysis of JPC Meetings}

\section{Data and Sampling}

The rest of the text presents an empirical examination of how deliberation works in the JPC meetings for five candidate countries, Bulgaria (2000-6), Croatia (2005-7), Lithuania (2000-4), Romania (2000-6) and Turkey (2000-7). Overall, our dataset is a collection of 45 transcripts from the fifth (2000-4) and sixth (2004-7) legislative periods. We cover a time frame of eight years, from 2000 until 2008. This period can be considered as 
the heyday of the enlargement project with the largest wave of enlargement taking place in 2004. The pre-2000 period is not analyzed due to the lack of data availability. The post 2008 period has not been included in the analysis for two main reasons: 2008 is considered as a turning point in the EU followed by the so-called 'enlargement fatigue'; and due to the crisis that emerged that year, EU governance drifted toward intergovernmentalism with less room left for parliamentary involvement. We suspect that these broader systemic factors have a negative impact on the functioning of inter-parliamentary co-operation, impairing the deliberative capacity of inter-parliamentary bodies, including JPCs.

With regard to case selection, we examined all inter-parliamentary meetings and selected transcripts from five candidate countries (Bulgaria, Croatia, Lithuania, Romania and Turkey). The five selected candidate countries under study challenge the EU position on certain policy areas, such as agriculture, energy or foreign policy. The presence of political controversy leading to different policy positions between the candidate countries and the EU serves as a litmus test that determines the two main modes of interaction characterizing inter-parliamentary meetings: deliberation and debate. The issue is how will these differences among different actors be perceived and how will these controversies be solved? Will JPC participants engage in deliberation (reason-giving arguments/ persuasion/dialogue/problem-solving) or debate (irreconcilable differences, conflict, winlose battles/strategic games)?

\section{Variable Measurements and Hypotheses}

Evaluation standards are used to measure deliberation; the dependent variables in the analysis are based on the work of Lord and Tamvaki (2013). The authors develop an updated 'Discourse Quality Index' (DQI) originally constructed by Steenbergen et al. (2003) to analyze parliamentary discourse in the British House of Commons. Lord and Tamvaki refine this index and use it to measure the quality of discourse in the EP. DQI contains five empirical criteria:

1. Respect and recognition (a) for other participants in plenary debates and (b) for other arguments employed in such debates (Do MEPs degrade, ignore, treat neutrally or explicitly respect (a) their interlocutors and (b) their arguments?); 2. Justification level (Do MEPs offer no reasons, one reason or two reasons for positions taken?); 3. Justification completeness (How far are justifications complete in their content advancing interests, values and rights?); 4. Justification inclusiveness (How far are justifications inclusive in their addressees promoting a national, European or global common good?); 5. Justification consequentiality (Do MEPs give or demand an account in their speeches?). (Lord and Tamvaki, 2013, pp. 38-9).

We apply these empirical criteria to our analysis of JPC transcripts introducing minor changes. First, JPCs are not decision-making bodies, so, there can be no tangible measure of accountability. Therefore, we exclude the last criterion of accountability. Second, we consider only extreme modes of communication that are easily recognizable and distinguishable from each other: high and low quality discourse corresponding to deliberation and debate, respectively. High quality discourse, which has a score of 1 for all the four criteria mentioned above, qualifies as deliberation. Actors who engage in deliberation explicitly respect their interlocutors and their arguments, offer reasons for positions taken, present complete and inclusive justifications based on some understanding of common 
good, rights or values. Low quality discourse, which has a score of 0 for all the four criteria mentioned above, qualifies as debate. Actors who engage in debate contradict their interlocutors with a tendency to degrade them and their positions, do not offer any reasons for the positions taken, or simply stick to narrowly defined national interests. Third, neutral speech is excluded from our dependent variable. Neutral speech refers to text that does not include any explicit reasoned arguments or forms of justification but take the form of expressions of gratitude or appreciation, procedural and ritualistic rhetoric or policy briefs. Neutral speech is ambiguous and also difficult to translate in quantifiable measures; therefore, we code only deliberation and debate as two extreme and easily distinguishable types of interaction. Due to this data cleaning, deliberation is re-coded as a continuous variable within the range $[0,1]$ and is calculated as the percentage of absolute value of deliberation over the sum of deliberation and debate in each transcript. Therefore, deliberation equals:

\section{Deliberation Ratio $=$ Deliberation $/($ Deliberation + Debate $)$.}

Next, we identify three main factors (as independent variables) that influence the quality of interaction in the JPC meetings: membership prospect, issue-area sensitivity and membership conditionality. First, membership prospect, which can be both positive and negative, serves as a proxy for power relations. In the literature on deliberation, participants in such settings are 'open to be persuaded by the better argument' and under these circumstances 'relations of power recede in the background' (Risse, 2004, p. 294). However, some scholars contend that power cannot be ignored even in deliberative settings (Schmidt, 2012; Shapiro, 1999). Since we aim to study the conditions under which deliberation takes place in general, and in JPC settings in particular, we use membership prospect to identify, measure and explain the nature of the power relations in deliberative settings. Thus in the case of JPC meetings, we take positive membership prospect as a proxy for equal power relations. Positive membership prospect includes speech acts that contain a clear promise of eventual membership foreseeing an exact date of accession through which candidate countries are frequently reminded of the fact that they will soon be EU Member States. In such type of interaction, representatives from the EU and candidate country alike perceive each other as trustworthy partners. Higher percentages of this variable represent those interactions among representatives of the EU and candidate country taking place in a setting among equals with minimum power asymmetries. Moreover, EU representatives emphasize the need for domestic transformation in the accession preparations for EU membership in the shortest time possible.

Negative membership prospect is a proxy for unequal power relations. In this case the roadmap for EU accession and full membership date are unclear in the exchange as observed in the transcripts. Such uncertainty reflects the participants' perception of each other as unequal parties and these perceptions breed an environment of distrust. Higher percentages of this variable represent unequal and asymmetric relations among participants. EU representatives assert power in articulating demands from the candidate country and candidate country representatives either reject or accept such demands.

Positive and negative membership prospect are continuous variables measured separately as percentages of total number of words representing each in the transcripts. The 
presence of positive membership prospect does not imply the absence of negative membership prospect, or vice versa. In order to test the role of membership prospect (hence the nature of power relations) on the deliberative capacity of the JPC venues we hypothesize that:

H1: As perceptions of equality increase, actors are more likely to make statements of positive membership prospect, thereby generating higher levels of deliberation and lower levels of debate in the JPC meetings.

H2: As perceptions of equality decrease, actors are more likely to make statements of negative membership prospect, thereby generating higher levels of debate and lower levels of deliberation in the JPC meetings.

A second factor that influences the quality of interaction in the JPC meetings is issue-area sensitivity. Although there exists in the literature examples of conceptualization of issue-area sensitivity, there exists no consensus on its different consequences. According to Magnette and Nicolaidis (2004, p. 394), 'deliberative dynamics played a role for issue-areas where preferences were less intense and consequences less predictable' - that is, non-controversial issue-areas. Blom-Hansen and Brandsma (2009, p. 722) suggest that issue-areas that are highly technical are more compatible with deliberation because in such cases national interests are not clear and experts need to justify their preferences using universal scientific evidence. Similarly, Naurin (2009) finds that the higher the seriousness of the issue for all parties involved, the higher are the political stakes and political pressure, making the participants less willing to deliberate. However, Lord and Tamvaki (2013) contend that high issue polarization, previously associated in the literature with less willingness among actors to appeal to shared values and understandings of common good, results in higher quality of deliberation. In this study, we observe that three main issue-area groups feature in the JPC meetings: economic (energy, economic growth, stability, privatization, sustainable development in agriculture); politico-cultural (women's rights, minority rights, freedom of expression, corruption, judiciary reform); and foreign policy (relations with candidate countries' neighbors or other countries in the region). Issue-area sensitivity refers to the degree of polarization around an issue-area (economic, politico-cultural, foreign policy), which is characterized by the intensity of the discussions in the JPC meetings (see Table 1). When intensity in discussions on each issue addressed is high, we code issue-area sensitivity for that issue-area as high. In such cases, parliamentarians tend to have fixed and narrowly defined preferences, often articulated around conflicting national interests. Under these circumstances, justifications presented by actors are less complete and less inclusive, triggering heated debates hindering deliberation.

The variable issue-area sensitivity is measured as the total sum of the percentages of each of the issue-area group coded as sensitive. For example, if politico-cultural issues are sensitive in JPC meeting transcripts of one country, then words where such matters are discussed are coded under issue-area sensitivity. Then these coded words are expressed as percentage of the total number of words in each transcript. We propose that:

H3: As issue-area sensitivity increases, actors are less likely to present inclusive and complete justifications, thereby generating higher levels of debate and lower levels of deliberation in the JPC meetings. 
Table 1: Classification Scheme and Coding Coverage (\%)

\begin{tabular}{lccccc}
\hline Codes & Lithuania & Bulgaria & Romania & Croatia & Turkey \\
\hline Deliberation & 11.21 & 9.5 & 10.54 & 10.43 & 8.39 \\
Reassure & 1.48 & 0.92 & 1.63 & 0.84 & 1.36 \\
Recommend & 4.89 & 4.81 & 5.39 & 6.13 & 2.85 \\
Concern & 1.72 & 1.44 & 1.52 & 0.84 & 1.79 \\
Suggest & 3.12 & 2.33 & 2 & 2.62 & 2.39 \\
Debate & 2.28 & 1.71 & 2.64 & 6.48 & 16.36 \\
Impose & 2.28 & 1.23 & 1.76 & 3.13 & 4.99 \\
Criticize & 0 & 0.48 & 0.88 & 3.35 & 11.37 \\
Membership prospect & 1.06 & 0.78 & 1 & 0.88 & 0.83 \\
Positive & 1.06 & 0.59 & 0.64 & 0.24 & 0 \\
Negative & 0 & 0.18 & 0.36 & 0.64 & 0.83 \\
Conditionality & 1.91 & 1.79 & 1.78 & 1.24 & 1.5 \\
Positive & 1.91 & 1.79 & 1.78 & 1.05 & 1.14 \\
Negative & 0 & 0 & 0 & 0.18 & 0.36 \\
Issue-area sensitivity & 20.04 & 24.5 & 21.06 & 26.89 & 47.6 \\
Economic & $20.04 *$ & $24.50^{*}$ & $21.06 *$ & 8.94 & 6.04 \\
Politico-cultural & 5.3 & 20.17 & 22.82 & $26.89^{*}$ & $25.58^{*}$ \\
Foreign policy & 15.16 & 5.66 & 4.36 & 10.53 & $22.02^{*}$ \\
Deliberation/(Deliberation + Debate) & 83 & 85 & 80 & 62 & 34 \\
Debate/(Deliberation + Debate) & 17 & 15 & 20 & 38 & 66 \\
\hline
\end{tabular}

Source: Authors' own calculations.

Note: *Indicates that an issue area is sensitive.

Third, we claim that membership conditionality - both positive and negative - has an impact on JPC participants' capacity to deliberate. In this study, positive and negative conditionality serve as proxies to gauge the presence (or absence) of constructive or consensus-oriented interaction. Different conceptualizations of constructive interaction have been proposed in the literature on other cases of deliberation in the EU. Actors' constructive or consensual style of interaction has been variously defined as 'cooperative problem solving' (Joerges and Neyer, 1997b; Joerges, 2006), 'constructive politics' (Steiner et al., 2005), 'co-ordinated action' (Jacobsson and Vifell, 2007), 'consensual attitude' (Naurin, 2009), 'co-ordinativeness' (Landwehr and Holzinger, 2010), agreements with a 'problem-solving character' (Risse and Kleine, 2010) and 'co-operative exchange' (Warntjen, 2010). Yet, there exists no agreement among scholars on whether we should consider constructive politics as indicative of deliberative interaction. In this study, we propose to examine membership conditionality in order to observe the effects of constructive politics on the capacity of JPC participants to deliberate. Membership conditionality represents instances of exchange among JPC participants where an incentive (positive conditionality) or a threat (negative conditionality) dominates interactions.

Positive conditionality represents instances where the candidate country is promised certain tangible or intangible benefits or rewards (such as trade concessions, aid, co-operation or association agreements) for facilitating the adoption, implementation or transformation of a policy during the accession process. Negative conditionality captures other instances where benefits of economic or political nature (such as association 
agreements and other forms of co-operative exchange) are scaled back, suspended or terminated. The latter takes the form of threats used to deter the candidate country from violating the conditions put forward by the EU. Both positive and negative conditionality are continuous variables expressed as the total sum of percentages of the total number of words representing positive and negative conditionality in each transcript. In accordance with these assumptions we propose that:

H4: As efforts to engage in constructive politics increase, actors are more likely to make statements that include incentives of joint and collaborative projects (positive conditionality), thereby generating higher levels of deliberation and lower levels of debate in the JPC meetings.

H5: As efforts to engage in constructive politics decrease, actors are more likely to make statements that include reduction, suspension or termination of benefits (negative conditionality), thereby generating higher levels of debate and lower levels of deliberation in the JPC meetings.

\section{Methods and Coding}

In order to code transcripts of the JPC meetings, we conducted a content analysis of the legislative transcripts. Content analysis is a research technique employed in order to (1) carry out systematic coding, and (2) formulate categories based on the meanings derived from the texts under scrutiny. In this study, we used NVivo to quantify categories of analysis by providing percentage frequencies of the coded speech or statements (a paragraph, a sentence or a group of words). We developed a classification scheme with categories that correspond to the dependent and independent variables included in the analysis. Deliberative speech includes high quality discourse, as defined by Lord and Tamvaki (2013), divided into four categories: reassurance, recommendation, suggestion and concern; whereas debate includes low quality discourse divided into two categories: imposition and criticism. Other categories are: positive membership prospect, negative membership prospect, issue-area sensitivity, positive conditionality and negative conditionality corresponding to our independent variables. The values of all these categories are measured at the transcript level, measured as percentages of the total number of words in each transcript. The percentages are then aggregated to the country level in order to allow for comparisons among the five country cases under investigation (see Table 1). Finally, we examine the relationship between our dependent and independent variables. For this purpose, we make use of Ordinary Least Square (OLS) regressions computed in STATA statistical software.

\section{Results and Discussion}

The content analysis of 45 JPC transcripts provided us with data, measured in frequencies. Descriptive statistics presented in Table 1 reveals the frequencies for all dependent and independent variables included in the analysis. As shown in Table 1, Lithuania scores the highest (11.21 per cent) whereas Turkey scores the lowest level of deliberation (8.39 per cent). There is clearly far more variation in the levels of debate across JPC meetings, with Turkey scoring the highest level of debate (16.36 per cent) and Bulgaria scoring the lowest level of debate (1.71 per cent). High levels of debate make it impossible for JPC meetings 
Table 2: Ordinary Least Square Estimates of Deliberation

\begin{tabular}{lr}
\hline & Deliberation \\
\hline Positive conditionality & $-0.28(0.78)$ \\
Negative conditionality & $-1.34(0.18)$ \\
Positive membership prospect & $2.35^{* *}(0.02)$ \\
Negative membership prospect & $0.86(0.39)$ \\
Issue area sensitivity & $-3.84^{* * *}(0.00)$ \\
Constant & $11.12(0.00)$ \\
Number of observations & 45 \\
$\mathrm{R}^{2}$ & 0.46 \\
\hline
\end{tabular}

Source: Authors' own calculations.

Notes: $\mathrm{P}$-values are reported in parentheses. $* * * \mathrm{p}<0.01 ; * * \mathrm{p}<0.05 ; * \mathrm{p}<0.1$.

with Turkey and Croatia to be finalized with constructive outcomes. In such cases, despite the presence of some level of deliberation, inter-parliamentary interaction turns out to be largely non-constructive and counter-productive in terms of outcomes. This is particularly the case in meetings with Turkey, which due to high level of debate end with a deadlock. This picture shows that deliberation should not be studied in isolation from other modes of interaction - in this case debate. High levels of debate not only hamper the capacity of the EU and candidate country representatives to deliberate, but also reverse the anticipated outcome of deliberation - that is, the ability to reach some common understanding, leading to impasse.

As stated in the previous section, deliberation is recoded as the ratio of deliberation over the sum of deliberation and debate found in each transcript. This adjustment excludes procedural, neutral speech and helps us understand the dynamic relationship between the two opposite modes of interaction: deliberation and debate. Recoded values of deliberation vary from 85 per cent in the case of Bulgaria to 34 per cent in the case of Turkey (see Table 1). The question arises as to what explains the variation in the levels of deliberation across JPC meetings. OLS regression results presented in Table 2 indicate that positive membership prospect is positively associated whereas issue-area sensitivity is negatively associated with deliberation. What do these results really mean?

First, the OLS analysis shows that positive membership prospect, as a proxy for equal power relations, is a significant factor in deterring participants from engaging in irresolvable debate over issues of EU accession. This result confirms the first hypothesis under scrutiny: when levels of positive membership prospect are higher, such as the case in JPC meetings with Lithuania, Bulgaria and Romania, lower levels of debate and relatively higher levels of deliberation are observed. Frequent reference and acknowledgment of the forthcoming membership reminds participants of their equal power relations and creates a legitimate basis for common understanding based on shared norms and values and an environment of trust; therefore, discouraging them to engage in debate. The absence of equal power relations leads to a spiral of unrestrained reciprocal mistrust that leads to a breakdown in communication, to the extent that deliberators may lose sight of the JPC's raison d'être.

Second, issue-area sensitivity turns out to be negatively associated with deliberation at a confidence level of 99 per cent. This result confirms our third hypothesis according to which increasing levels of issue-area sensitivity make the arguments presented by 
participants less inclusive and complete leading to higher levels of debate and lower levels of deliberation. Turkey displays an exceptionally high level of issue-area sensitivity within the politico-cultural and foreign policy areas. The most controversial issue is human rights, including non-Muslim minority rights and ethnic rights (that is, rights of the Kurdish population); abolition of death penalty; the Cyprus issue; the questions on Armenian genocide and Turkey-Greece relations. The debates revolving around the Cyprus issue are highly sensitive for Turkish delegates and MEPs with a Greek and Cypriot nationality. Evidence from the deliberations in the JPC meetings suggests that not only Turkish delegates, but also MEPs who are supposed to follow supranational norms and values, reproduce existing national positions, thus precipitating conflict, rather than promoting mutually acceptable solutions. As a result, an uncompromising tone on sensitive political issue-areas dominates the agenda.

One interesting aspect of these findings is the transformation of JPCs from forums of deliberation into arenas of contentious debate - that is, the emergence of debate in an inherently deliberative setting or most likely case of deliberation. Such findings suggest that deliberative institutions are not fixed structures that would inherently and exclusively facilitate deliberation as would be initially expected. Deliberative institutions are continually constructed through a process of discursive participation, which are shaped by conditions that impact the interaction among participants as evidenced by the findings from the inter-parliamentary interaction in the JPCs.

\section{Conclusions}

This study is an empirical analysis of JPCs which are innovative, longstanding and, at the same time, understudied instruments of inter-parliamentary co-operation operating in the context of EU enlargement process. Due to their multilevel network structure, diversified political environment, absence of voting mechanisms, presence of a flexible agenda and in-camera setting with some degree of transparency and publicity, JPCs can be considered as typical venues of deliberation. Yet, we go along with the recent calls in the literature on deliberative politics and go one step further to study how deliberative ideals are translated into institutional practices in settings that would typically stimulate deliberation. Empirical research on deliberative politics is still in its infancy. We therefore aim to advance the state-of-the-art by identifying a set of empirical conditions under which deliberation takes place in the JPCs in practice.

Based on our findings, we identify two conditions for deliberative mode of interaction. First, higher levels of deliberation are associated with high positive membership prospect, which serves as a proxy for equal power relations. The study of JPC meetings alerts research on deliberation to the result that equal power relations need not be taken for granted or sufficient for deliberative processes to flourish. To the contrary, equal power relations need to be sustained throughout the process of deliberation in the deliberative setting with participants consistently sending signals of equality to one another and emphasizing shared sense of (existing and prospective) identity among themselves. Under such conditions participants exhibit more trustful behaviour; this in turn substantially decreases the likelihood of debate and eventually increases the deliberative capacity of the JPCs. Second, deliberation is also a function of the sensitivity of the issues being discussed by participants. Low issue-area sensitivity entails more complete and inclusive 
argumentation, which decreases the levels of debate and eventually fosters the capacity of participants to deliberate. On the contrary, high issue-area sensitivity serves as a catalyst for dominance of politics of national identity and national conflicting preferences of participants even in multilevel forums such as JPCs, which combine elements of national legitimacy and sovereignty with supranational values. Under conditions of debate, national identities not only do not fuse into supranational roles, but also prompt representatives of the EP and national parliaments to revert to defending narrowly defined interests leading up to conflict and mutual distrust. This scenario is often observed in parliamentary meetings with Turkey, where JPCs turn into arenas of debate away from the intended forums of deliberation. In such cases, JPCs may lapse into more venues of debate (than deliberation) under conditions of high issue-area sensitivity - this finding is at odds with the scholarly expectation that JPCs would potentially preclude conflictridden forms of interaction. Hence we conclude that research needs to also look at conditional deliberation, which aims to identify underlying factors that shape deliberative policy-making.

Our analysis of the JPC transcripts shows that interaction within a parliamentary setting can never be exclusively deliberative even if the setting qualifies for ideal attributes for deliberative policy-making. Studying the dynamic relationship between deliberation and other modes of interaction (such as debate) rather than focusing on deliberative processes in isolation from other modes of interaction helps us understand conditions for deliberative policy-making better. In the case of JPCs, the two modes of interaction under investigation - 'deliberation' and 'debate' - influence each other similar to two sides of a feedback loop. High levels of debate not only hinder the capacity of parliamentarians to deliberate further, but also reverse the positive impact of the deliberation carried out thus far, thereby leading to deadlock and invalidating the role of JPCs as channels for conflict mediation and problem-solving through deliberation. Moreover, the transformation of JPCs from forums of deliberation into arenas of debate under certain conditions suggests that inherently deliberative settings can become 'undeliberative' with participants behaving in adversarial, emotional and irrational ways. Hence, our findings suggest that further empirical studies are needed examining unfolding processes of institutionalization of deliberation more so than chasing after the formally and externally fixed deliberative institutions in different settings such as those in the EU themselves.

The lesson of this study is that deliberation is conditional since we observe that even the most likely and enduring institutional settings for deliberation harbor debate. Based on our findings on the more likely cases of deliberation in JPCs, we can derive two sets of conclusions for empirical studies on conditions for deliberation to be examined in less likely cases. First, in particular, in JPCs where debate crowds out deliberation due to low positive membership prospect (and therefore unequal power relations) and instances of high sensitivity issue-areas (where clashes of national identity, preferences and interests ensue) as featuring in transcripts for Turkey, the way to reverse the ratio of debate to deliberation is through satisfying the conditions of deliberation: increase positive membership prospect fostering equal power relations among participants and smoothing out issue-area sensitivities liberating these settings from conflict-ridden national identities, preferences and interests for an inclusive interaction. Second, at a more general level, for settings other than the particular case of JPCs, all institutionalized interactive settings have 
the potential of becoming deliberative (that is, with a higher ratio of deliberation in the interaction) as long as the particular conditions tipping the balance in favour of deliberative interaction are sustained. Our findings highlight fostering equal power relations and toning down polarized identities, preferences and interests in interactions as conditions for facilitating deliberation in interactive, multi-actor and transnational settings. However, we expect that different interactive settings may involve distinct modi operandi requiring additional conditions inviting further empirical research.

In the context of lingering enlargement fatigue, growing Euroscepticism, faltering intra-EU interaction and precarious relations with neighbours in a time of crisis, interparliamentary co-operation in forums such as JPCs has the potential to nurture reciprocal trust, enhance collaboration and facilitate policy co-ordination between the EU and candidate countries. Considering the broader political context, inter-parliamentary co-operation is not, in Weber's words, solely a 'little cog in a machine', but has the qualities to constitute a building block of the EU integration process. As this research shows, deliberation, even in the most likely settings, is a scarce resource and in its absence conflict-ridden interaction ensues. Therefore, further research for identifying conditions for deliberation in different settings would help policy-makers craft environments of constructive interaction.

Correspondence:

Saime Ozcurumez

Department of Political Science and Public Administration

Bilkent University

Ankara 06800

Turkey

email: saime@bilkent.edu.tr

\section{References}

Bohman, J.F. (1998) 'Survey Article: The Coming of Age of Deliberative Democracy'. Journal of Political Philosophy, Vol. 6, pp. 400-25.

Bohman, J.F. and Rehg, W. (1997) Deliberative Democracy: Essays on Reason and Politics (Cambridge, MA: MIT Press).

Blom-Hansen, J. and Brandsma, G.J. (2009) 'The EU Comitology System: Intergovernmental Bargaining and Deliberative Supranationalism?'. JCMS, Vol. 47, pp. 719-40.

Chambers, S. (2003) 'Deliberative Democratic Theory'. Annual Review of Political Science, Vol. 6, pp. 307-26.

Closa, C. and Fossum, J.E. (2005) 'Deliberative Constitutional Politics and the Turn towards a Norms-Based Legitimacy of the EU Constitution'. European Law Journal, Vol. 11, pp. 41131.

Cohen, J. (1996) 'Procedure and Substance in Deliberative Democracy'. In Benhabib, S. (ed.) Democracy and Difference: Contesting the Boundaries of the Political (Princeton, NJ: Princeton University Press).

Cohen, J. and Sabel, C.F. (1997) 'Directly-Deliberative Polyarchy'. European Law Journal, Vol. 3, pp. 313-42.

Cohen, J. and Sabel, C.F. (2003) 'Sovereignty and Solidarity: EU and US'. In Zeitlin J. and Trubek, D. (eds) Governing Work and Welfare in a New Economy: European and American Experiments (Oxford: Oxford University Press). 
Crum, B. and Fossum, J.E. (2009) 'The Multilevel Parliamentary Field: A Framework for Theorizing Representative Democracy in the EU'. European Political Science Review, Vol. 1, pp. 249-71.

Dryzek, J.S. (2000) Deliberative Democracy and Beyond: Liberals, Critics, Contestation (Oxford: Oxford University Press).

Elster, J. (1998) Deliberative Democracy (Cambridge: Cambridge University Press).

Eriksen, E.O. (2000) 'Deliberative Supranationalism in the EU'. In Eriksen, E.O. and Fossum, J.E. (eds) Democracy in the European Union: Integration through Deliberation? (London: Routledge).

Eriksen, E.O. and Fossum, J.E. (2002) 'Democracy through Strong Publics in the European Union?'. JCMS, Vol. 40, pp. 401-24.

Gerstenberg, O. and Sabel, C.F. (2002) 'Directly-Deliberative Polyarchy: An Institutional Ideal for Europe?'. In Joerges, C. and Dehousse, R. (eds) Good Governance in Europe's Integrated Market (Oxford: Oxford University Press).

Gutmann, A. and Thompson, D. (1996) Democracy and Disagreement: Why Moral Conflict Cannot be Avoided in Politics and What Should Be Done about It (Cambridge, MA: Harvard University Press).

Habermas, J. (1996a) Betweeen Facts and Norms: Contributions to a Discourse Theory of Law and Democracy (Cambridge, MA: MIT Press).

Habermas, J. (1996b) 'Three Nomative Models of Democracy'. In Benhabib, S. (ed.) Democracy and Difference: Contesting the Boundaries of the Political (Princeton, NJ: Princeton University Press).

Habermas, J. (1998) On the Pragmatics of Communication (Cambridge, MA: MIT Press).

Hurrelmann, A. and DeBardeleben, J. (2009) 'Democratic Dilemmas in EU Multilevel Governance: Untangling the Gordian Knot'. European Political Science Review, Vol. 1, pp. 229-47.

Jacobsson, K. and Vifell, Å. (2005) 'Soft Governance, Employment Policy and Committee Deliberation'. In Eriksen, E.O. (ed.) Making the Euro-Polity: Reflexive Integration in the EU (London: Routledge).

Jacobsson, K. and Vifell, Å. (2007) 'Deliberative Transnationalism? Analysing the Role of Committee Interaction in Soft Coordination'. In Linsenmann, I., Meyer. C.O. and Wessels, W. (eds) Economic Government of the EU: A Balance Sheet of New Modes of Policy Coordination (Basingstoke: Palgrave Macmillan).

Joerges, C. (2002) 'Deliberative Supranationalism: Two Defences'. European Law Journal, Vol. 8, pp. $133-51$.

Joerges, C. (2006) 'Deliberative Political Processes Revisited: What Have We Learnt about the Legitimacy of Supranational Decision-Making'. JCMS, Vol. 44, pp. 779-802.

Joerges, C. and Neyer, J. (1997a) 'From Intergovernmental Bargaining to Deliberative Political Processes: The Constitutionalisation of Comitology'. European Law Journal, Vol. 3, pp. 273-99.

Joerges, C. and Neyer, J. (1997b) 'Transforming Strategic Interaction into Deliberative ProblemSolving: European Comitology in the Foodstuffs Sector'. Journal of European Public Policy, Vol. 4, pp. 609-25.

Lafont, C. (2006) 'Is the Ideal of a Deliberative Democracy Coherent?'. In Besson, S. and Martí, J.L. (eds) Deliberative Democracy and Its Discontents. pp. 1-25 (Hampshire: Ashgate Publishing Ltd).

Landwehr, C. and Holzinger, K. (2010) 'Institutional Determinants of Deliberative Interaction'. European Political Science Review, Vol. 2, pp. 373-400. 
Lord, C. and Tamvaki, D. (2013) 'The Politics of Justification? Applying the Discourse Quality Index to the Study of the European Parliament'. European Political Science Review, Vol. 5, pp. $27-54$.

Macedo, S. (1999) Deliberative Politics: Essays on Democracy and Disagreement (Oxford: Oxford University Press).

Magnette, P. and Nicolaidis, K. (2004) 'The European Convention: Bargaining in the Shadow of Rhetoric'. West European Politics, Vol. 27, pp. 381-404.

Maurer, A. (2003) 'Less Bargaining - More Deliberation: The Convention Method for Enhancing EU Democracy'. International Politics and Society, Vol. 1, pp. 167-90.

Naurin, D. (2009) 'Most Common When Least Important: Deliberation in the European Union Council of Ministers'. British Journal of Political Science, Vol. 40, pp. 31-50.

Panke, D. (2006) 'More Arguing than Bargaining? The Institutional Designs of the European Convention and Intergovernmental Conferences Compared'. Journal of European Integration, Vol. 28, pp. 357-79.

Pollack, M.A. and Shaffer, G.C. (2008) 'Risk Regulation, GMOs and the Limits of Deliberation'. In Naurin, D. and Wallace, H. (eds) Unveiling the Council of the European Union: Games Governments Play in Brussels (Basingstoke: Palgrave Macmillan).

Puetter, U. (2003) 'Informal Circles of Ministers: A Way Out of the EU's Institutional Dilemmas?'. European Law Journal, Vol. 9, pp. 109-24.

Puetter, U. (2012) 'Europe's Deliberative Intergovernmentalism: The Role of the Council and European Council in EU Economic Governance'. Journal of European Public Policy, Vol. 19, pp. 161-78.

Rawls, J. (1993) Political Liberalism (New York: Colombia University Press).

Risse, T. (2004) 'Global Governance and Communicative Action'. Government and Opposition, Vol. 39, pp. 288-313.

Risse, T. and Kleine, M. (2007) 'Assessing the Legitimacy of the EU's Treaty Revision Methods'. JCMS, Vol. 45, pp. 69-80.

Risse, T. and Kleine, M. (2010) 'Deliberation in Negotiations'. Journal of European Public Policy, Vol. 17, pp. 708-26.

Rittberger, B. (2012) 'Institutionalizing Representative Democracy in the European Union: The Case of the European Parliament'. JCMS, Vol. 50, pp. 18-37.

Schmidt, V.A. (2012) 'Democracy and Legitimacy in the European Union Revisited: Input, Output and "Throughput". Political Studies, Vol. 61, pp. 2-22.

Shapiro, I. (1999) 'Enough about Deliberation: Politics is about Interests and Power'. In Macedo, S. (ed.) Deliberative Politics: Essays on Democracy and Disagreement (Oxford: Oxford University Press).

Steenbergen, M.R., Bächtiger, A., Spörndli, M. and Steiner, J. (2003) 'Measuring Political Deliberation: A Discourse Quality Index'. Comparative European Politics, Vol. 1, pp. 21-48.

Steiner, J., Bächtiger, A., Spörndli, M. and Steenbergen, M.R. (2005) Deliberative Politics in Action: Analyzing Parliamentary Discourse (Cambridge: Cambridge University Press).

Thompson, D.F. (2008) 'Deliberative Democratic Theory and Empirical Political Science'. American Review of Political Science, Vol. 11, pp. 497-520.

Vink, E. (2007) 'Multi-Level Democracy: Deliberative or Agonistic? The Search for Appropriate Normative Standards'. Journal of European Integration, Vol. 29, pp. 303-22.

Warntjen, A. (2010) 'Between Bargaining and Deliberation: Decision-Making in the Council of the European Union'. Journal of European Public Policy, Vol. 17, pp. 665-79. 